02

\title{
Люминесценция дитолуоилметаната дифторида бора. Образование $\mathrm{J}$-агрегатов
}

\author{
(C) А.Г. Мирочник, Е.В. Федоренко, А.Ю. Белолипцев \\ Институт химии Дальневосточного отделения РАН, \\ 690022 Владивосток, Россия \\ e-mail: gev@ich.dvo.ru
}

Поступила в редакцию 27.05.2021 г.

В окончательной редакции 21.08.2021 г.

Принята к публикации 06.09.2021 г.

Изучены процессы формирования Ј-агрегатов при растворении кристаллов 2,2-дифторо-4,6-ди(4'метилфенил)-1,3,2-диоксаборин (1) и последующей их диссоциации методами абсорбционной и люминесцентной спектроскопии и квантово-химического моделирования. Показано, что в растворах 1 наблюдаются два люминесцентных центра: мономерной люминесценции и люминесценции Ј-агрегатов (дуальная люминесценция). С течением времени наблюдается эволюция спектров поглощения, возбуждения люминесценции и люминесценции, свидетельствующая о медленной диссоциации J-агрегатов.

Ключевые слова: люминесценция, спектры поглощения, комплексы дифторида бора, Ј-агрегаты.

DOI: $10.21883 /$ OS.2022.02.52006.1717-21

\section{Введение}

$\beta$-Дикетонаты дифторида бора - это ярко люминесцирующие сильно полярные соединения, обладающие способностью к самоорганизации: эксимерообразованию $[1,2]$, образованию гелей $[3,4]$, образованию фотостабильных эксимеров [5] и эксиплексов [6] в полимерных матрицах. Способность к самоорганизации обусловливает такие свойства, как механохромизм, термохромизм [7,8], размернозависимая люминесценция [9]. В связи с этим вызывает интерес образование агрегатов молекулами $\beta$-дикетонатов дифторида бора в растворах и полимерных матрицах и формирование новых люминесцентных центров на их основе.

Как правило $[10,11]$, полоса поглощения агрегатов не наблюдается, но в спектре возбуждения люминесценции присутствует интенсивная длинноволновая полоса, соответствующая возбуждению слабосвязанных агрегатов, подобных описанным Вебером [12]. Ранее [13] нам удалось обнаружить соединение, для которого J-агрегаты регистрируются в спектрах поглощения, 2,2-дифторо-4-метилнафто-[2,1-е]-1,3,2-диоксаборин. Это связано с тем, что молекула является жесткой (состоит из двух конденсированных ароматических колец и хелатного квазиароматического), не имеет объемных групп (или заместителей). В настоящем сообщении представлен еще один редкий (для $\beta$-дикетонатов дифторида бора) пример, позволяющий наблюдать образование Ј-агрегатов в растворе: 2,2-дифторо-4,6-ди(4'метилфенил)-1,3,2-диоксаборин (1) (схема).<smiles>CC(=O)C1(F)C=C(c2ccc(C)cc2)C=C(c2ccc(C)cc2)O1</smiles>

\section{Экспериментальная часть}

Для приготовления растворов использовали хлороформ производства ЭКОС-1 без предварительной очистки. 2,2-Дифторо-4,6-ди(4'-метилфенил)-1,3,2диоксаборин был получен и очищен по методике, приведенной в работе [14].

Спектры поглощения регистрировали на спектрометpe Shimadzu UV-2550. Спектры возбуждения люминесценции и люминесценции регистрировали на спектрофлуориметре Shimadzu-RF5301 в кюветах $10 \times 10 \mathrm{~mm}$. При исследовании зависимости спектра люминесценции от длины волны возбуждающего света и спектров возбуждения люминесценции от длины волны регистрации люминесценции концентрированных растворов для исключения эффекта внутреннего фильтра спектры записывали при фронтальном расположении кюветы $10 \times 1 \mathrm{~mm}$.

Модельные квантово-химические расчеты одиночной молекулы и димеров дитолуилметаната дифторида бора были проведены с использованием программного комплекса Gamess [15] методом ОХФ ССП (ограниченного Хартри-Фока самосогласованного поля) в базиce 6-311G(p,d) с добавлением функционала плотности 

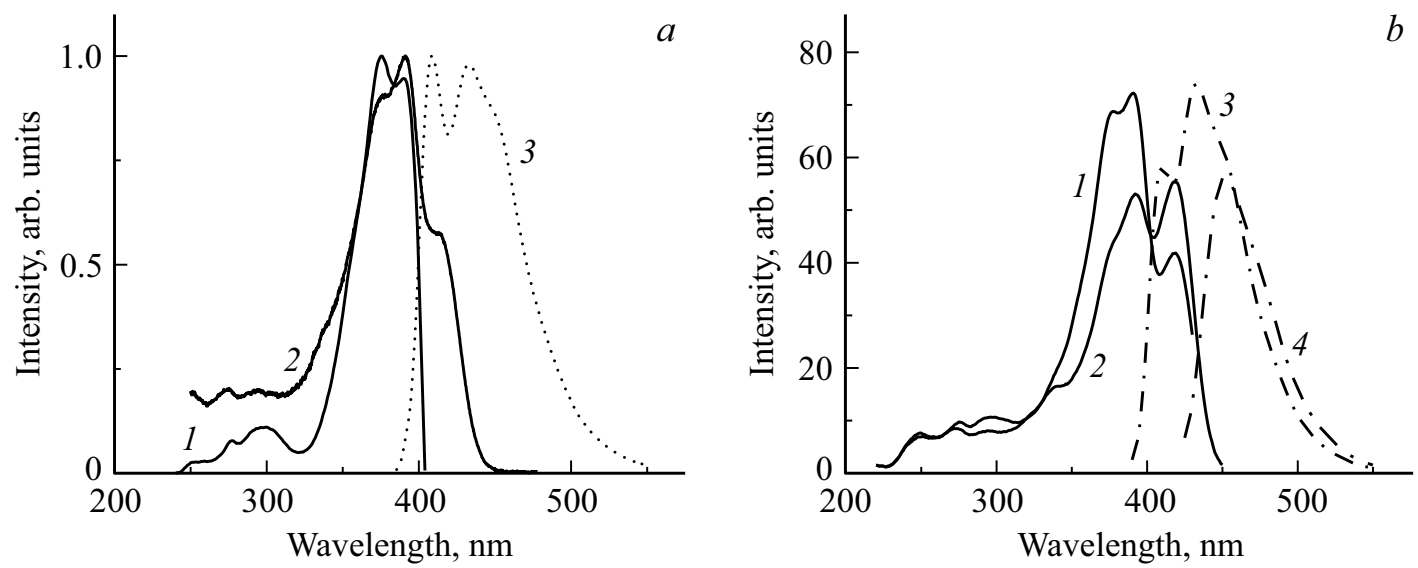

Рис. 1. (а) Нормированные спектры поглощения раствора 1 в хлороформе: $1-C=1 \cdot 10^{-6} \mathrm{~mol} \cdot \mathrm{L}^{-1}, 2-C=5 \cdot 10^{-6} \mathrm{~mol} \cdot \mathrm{L}^{-1}$; 3 - спектр люминесценции раствора с $C=1 \cdot 10^{-6} \mathrm{~mol} \cdot \mathrm{L}^{-1}$. (b) Спектры раствора 1 в хлороформе $\mathrm{c} C=5 \cdot 10^{-6} \mathrm{~mol} \cdot \mathrm{L}^{-1}$ : возбуждения люминесценции: $1-\lambda_{\mathrm{reg}}=440 \mathrm{~nm}, 2-\lambda_{\mathrm{reg}}=470 \mathrm{~nm}$; люминесценции: $3-\lambda_{\mathrm{ex}}=380 \mathrm{~nm}, 4-\lambda_{\mathrm{ex}}=417 \mathrm{~nm}$.

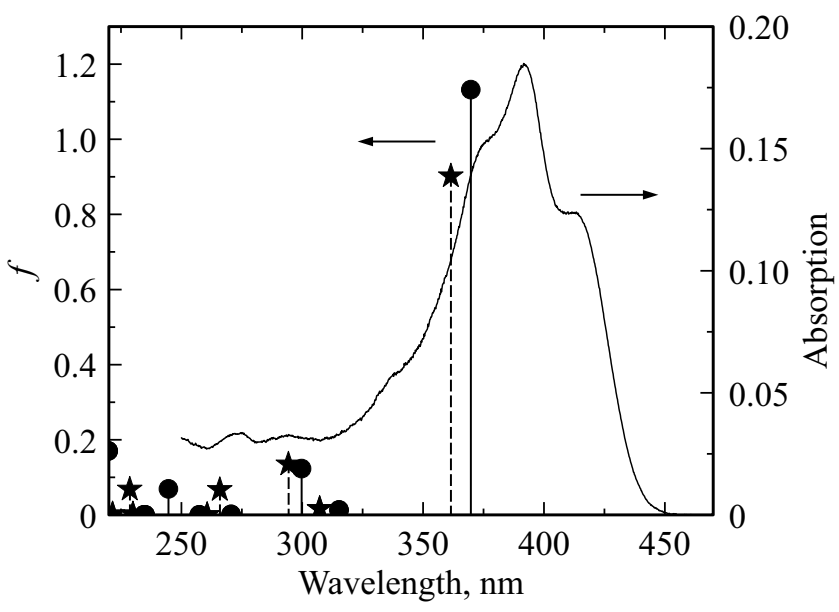

Рис. 2. Спектры поглощения раствора 1 в хлороформе: экспериментальный $C=5 \cdot 10^{-6} \mathrm{~mol} \cdot \mathrm{L}^{-1}$ (сплошная кривая), расчитанный для эксперименттальной геометрии (звездочки), расчитанный для оптимизированной геометрии (кружочки).

B3LIP в экспериментальной геометрии. Геометрия молекулы полностью оптимизирована. Эффект растворителя учитывали с помощью модели поляризуемого континуума (polarizable continuum model, PCM).

\section{Результаты и обсуждение}

Для записи спектров поглощения $\mathbf{1}$ был приготовлен раствор в хлороформе с концентрацией $C=5 \cdot 10^{-6} \mathrm{~mol} \cdot \mathrm{L}^{-1}$; раствор готовили последовательным разбавлением из раствора с $C=1 \cdot 10^{-3} \mathrm{~mol} \cdot \mathrm{L}^{-1}$. Оптическая плотность раствора составляет 0.018 , что, казалось бы, позволяет рассматривать раствор как разбавленный и не учитывать межмолекулярные взаимодействия. В спектре поглощения аналогично спектру дибензоилметаната дифторида бора [10] наблюдается интенсивная полоса с выраженной колебательной структурой $(377,393 \mathrm{~nm}$, рис. 1,a). Кроме этого, в спектре присутствует плечо $412 \mathrm{~nm}$, нехарактерное для $\beta$ дикетонатов дифторида бора $[11,16]$ и отсутствующее в теоретическом спектре (рис. 1,2). При понижении концентрации раствора до $10^{-6} \mathrm{~mol} \cdot \mathrm{L}^{-1}$ полоса $412 \mathrm{~nm}$ исчезает, что позволяет отнести ее к поглощению межмолекулярных агрегатов (Ј-агрегатов).

В спектре мономерной люминесценции $\mathbf{1}$ $\left(10^{-6} \mathrm{~mol} \cdot \mathrm{L}^{-1}\right)$, как и в спектре поглощения, наблюдается колебательная структура (рис. $1, a$ ), спектр возбуждения соответствует спектру поглощения. При повышении концентрации раствора до $5 \cdot 10^{-6} \mathrm{~mol} \cdot \mathrm{L}^{-1}$ в спектре возбуждения люминесценции появляется полоса $422 \mathrm{~nm}$, соответствующая полосе поглощения $412 \mathrm{~nm}$. При этом появляется дуальная люминесценция: при изменении длины волны регистрации с 440 на $470 \mathrm{~nm}$ в

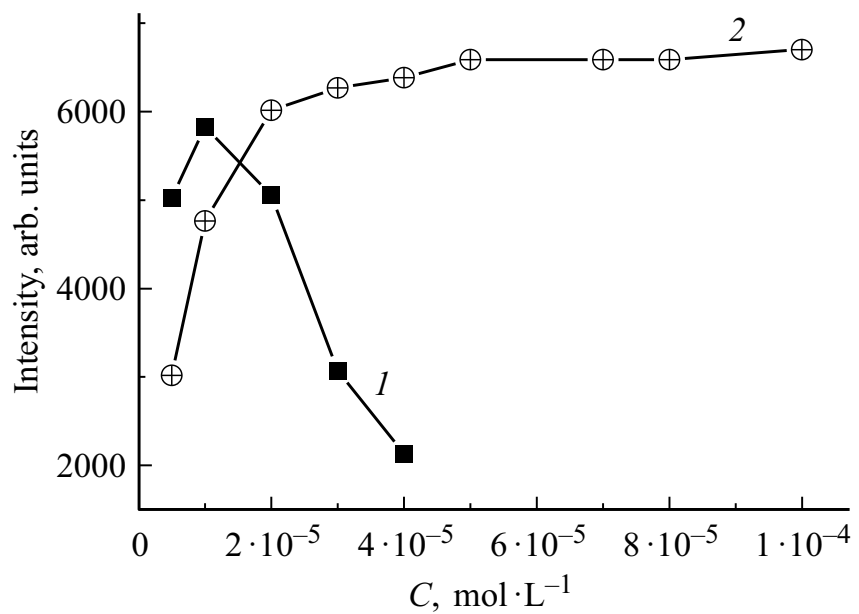

Рис. 3. Зависимость интегральной интенсивности люминесценции свежеприготовленного раствора 1 от концентрации люминофора при разных длинах волн возбуждающего света: $1-\lambda_{\mathrm{ex}}=380 \mathrm{~nm} ; 2-\lambda_{\mathrm{ex}}=430 \mathrm{~nm}$. 

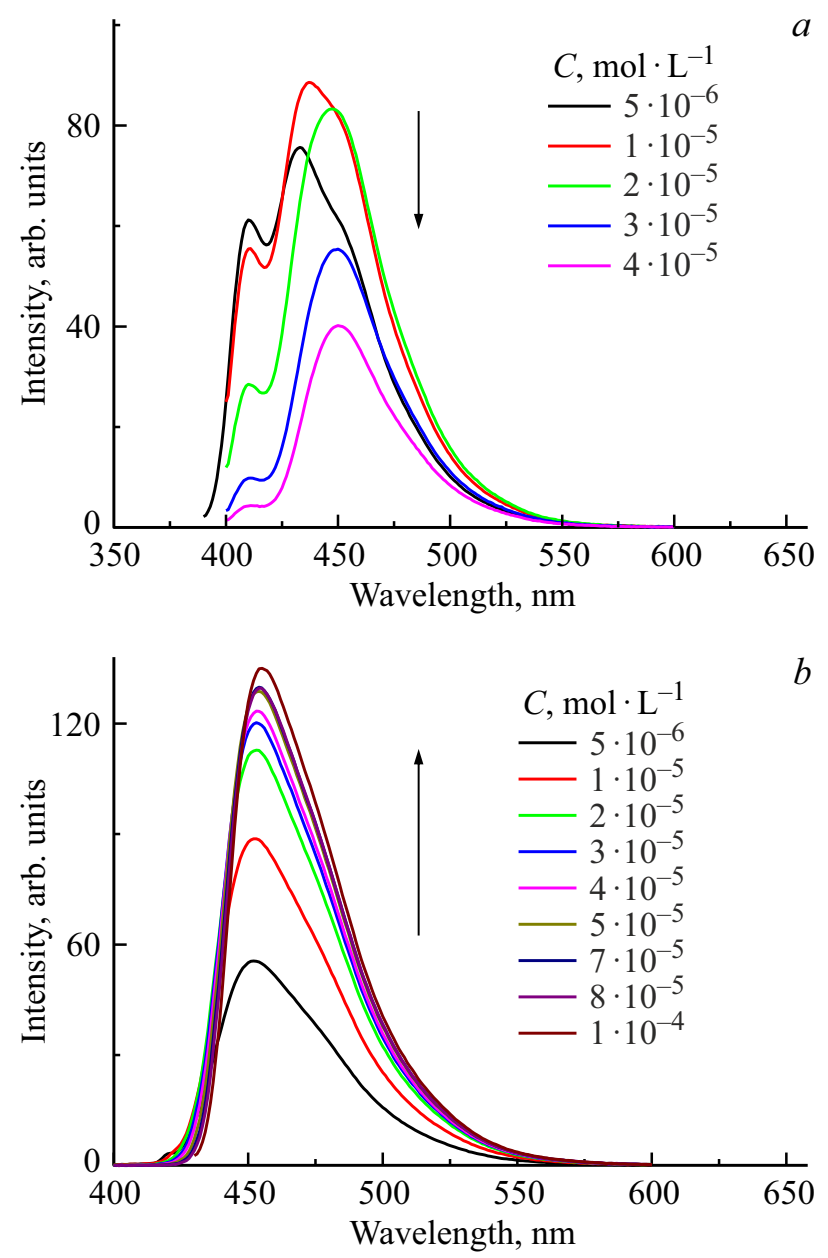

Рис. 4. Спектры люминесценции растворов 1 в хлороформе: (a) $-\lambda_{\mathrm{ex}}=380 \mathrm{~nm} ;(b)-\lambda_{\mathrm{ex}}=430 \mathrm{~nm}$.

спектре возбуждения люминесценции значительно возрастает полоса возбуждения агрегатов (рис. $1, b)$. Спектр люминесценции, записанный при $\lambda_{\mathrm{ex}}=415 \mathrm{~nm}$ (длина волны поглощения агрегатов), батохромно смещен относительно спектра, записанного при $\lambda_{\mathrm{ex}}=380 \mathrm{~nm}$ (длина волны возбуждения мономеров) (рис. 1,b). Таким образом, в растворах 1 наблюдаются два люминесцентных центра: мономерной люминесценции $\left(\lambda_{\mathrm{ex}}=380 \mathrm{~nm}, \lambda_{\text {lum }}=407\right.$ и $\left.430 \mathrm{~nm}\right)$ и люминесценции J-агрегатов $\left(\lambda_{\mathrm{ex}}=420 \mathrm{~nm}, \lambda_{\text {lum }}=450 \mathrm{~nm}\right)$.

Подтверждением наличия двух центров люминесценции в растворах 1 (мономерной и люминесценции J-агрегатов) является различный характер концентрационной зависимости интенсивности люминесценции от длины волны возбуждающего света (рис. 3,4). Зависимость эффективности концентрационного тушения от длины волны возбуждающего света описана в [17] и объяснена образованием межмолекулярных агрегатов, возбуждаемых другой длиной волны, отличной от максимума спектра поглощения одиночных молекул.

При хранении растворов 1 в хлороформе в течение двух дней наблюдается обесцвечивание бледно-желтых
Полные энергии $\left(E_{\text {tot }}\right)$ мономера и димеров $\mathbf{1}$, рассчитанные методом РСМ, и энергии образования димеров $\left(\Delta E_{\text {form }}\right)$

\begin{tabular}{c|c|c}
\hline & $E_{\mathrm{tot}}$, at.units & $\Delta E_{\text {form }}$, at.units \\
\cline { 2 - 3 } Мономер & -1031.45725 & \\
\hline Димер „голова-голова“ & -2062.9142 & -0.0003 \\
\hline Димер „голова-хвост“ & -2062.9174 & -0.0030
\end{tabular}

растворов и гипсохромное смещение спектров люминесценции (рис. 5). Изменение спектральных характеристик не связано с химическим разложением люминофора: данные ТCX (тонкослойная хроматография) сравнения и ИК спектроскопии веществ в свежеприготовленном и простоявшем два дня растворах идентичны.

В спектре поглощения обесцвеченного раствора исчезает полоса поглощения Ј-агрегатов (рис. 5, a), при этом происходит гипсохромное смещение максимума спектра поглощения. Спектры возбуждения люминесценции и люминесценции также смещаются в голубую область и для растворов с концентрацией $5 \cdot 10^{-6}$ и $10^{-5} \mathrm{~mol} \cdot \mathrm{L}^{-1}$ совпадают со спектрами мономерной люминесценции раствора с $C=10^{-6} \mathrm{~mol} \cdot \mathrm{L}^{-1}$ (рис. $1, a$ и $\left.5, b\right)$. Наблюдаемая эволюция спектров свидетельствует о диссоциации J-агрегатов в разбавленных растворах 1 с течением времени.

Медленная диссоциация 1 обусловлена особенностями его кристаллического строения. Кристаллическое строение 1 определено в работе [14]. CIF-файл депонирован в CCDC под номером 23428. Несмотря на наличие в обоих фенильных кольцах в пара-положении одинаковых заместителей (метильных групп), в кристалле молекула 1 является несимметричной [13]. Как правило, небольшое искажение молекулы происходит вследствие достижения плотнейшей упаковки в кристалле [18]. Молекулы 1 в кристалле организованы в скошенные стопки (рис. 6,a) [13]. В структуре 1 выделяются следующие короткие контакты: между атомами водорода метильных групп и ароматическими кольцами соседних молекул (рис. 6, $a$ ); между атомами водорода фенильных колец и атомами фтора соседней молекулы (рис. 6, $b$ ). В стопке это соответствует $\pi$-стекинг- и С-H... стекинг-взаимодействиям. Между собой стопки связаны слабой водородной связью $\mathrm{C}-\mathrm{H}$. . .F, характерной для $\beta$ дикетонатов дифторида бора и играющей важную роль в самоорганизации их молекул [19]. Ряды молекул, связанных С-Н. ..F-связью, образуют слои (рис. $6, b)$.

Люминесцентные свойства кристаллов $1\left(\lambda_{\mathrm{ex}}=485 \mathrm{~nm}\right.$, $\left.\lambda_{\text {lum }}=520 \mathrm{~nm}\right)$ обусловлены формированием Ј-агрегатов в структуре кристалла и эксимеров на их основе [14]. J-агрегаты в свою очередь состоят из димеров, являющихся эксимерными ловушками (рис. 6,a).

Обычно при растворении кристалла учитывается энергия, необходимая для отрыва молекулы от кристалла, и энергия сольватации оторвавшейся молекулы. Для 1 при 

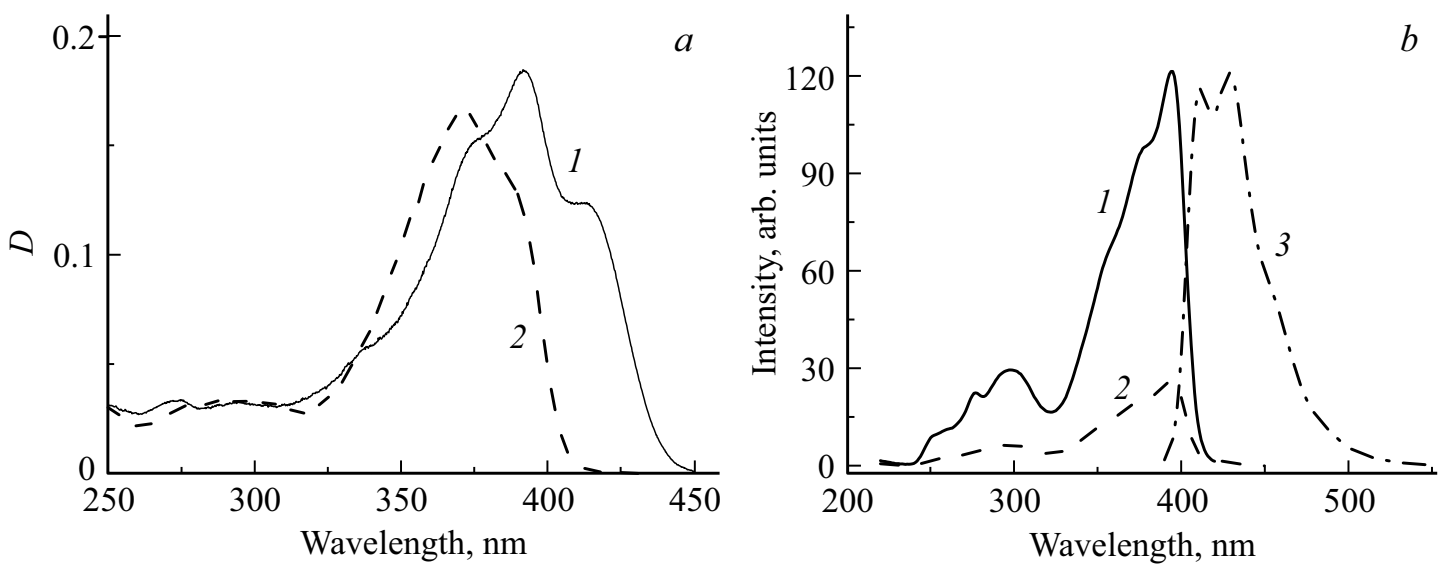

Pис. 5. (a) Спектры поглощения раствора 1 в хлороформе $C=5 \cdot 10^{-6} \mathrm{~mol} \cdot \mathrm{L}^{-1}: 1-$ свежеприготовленный, $2-$ через два дня после приготовления; $(b)$ спектры возбуждения люминесценции раствора 1 в хлороформе с $C=5 \cdot 10^{-6} \mathrm{~mol} \cdot \mathrm{L}^{-1}$ через два дня после приготовления: $1-\lambda_{\text {reg }}=430 \mathrm{~nm}, 2-\lambda_{\text {reg }}=470 \mathrm{~nm} ; 3-$ спектр люминесценции, $\lambda_{\mathrm{ex}}=380 \mathrm{~nm}$.
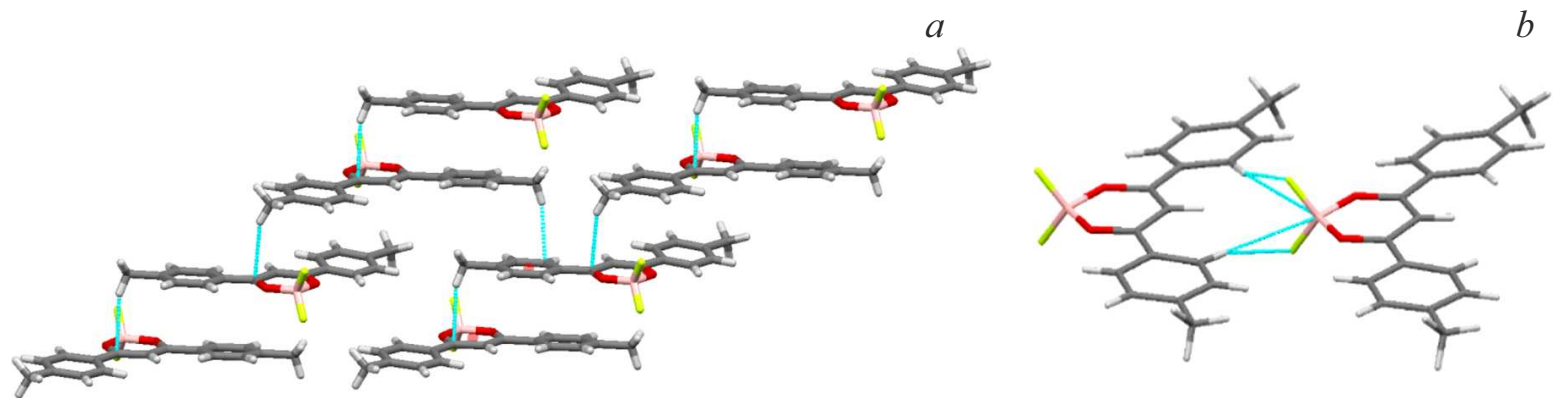

Рис. 6. Межмолекулярные взаимодействия в кристалле 1: (a) скошенные стопки, показаны короткие контакты между молекулами, соответствующие $\mathrm{C}-\mathrm{H} \ldots \pi$-стекинг-взаимодействию, $(b)$ фрагмент слоя молекул, показаны водородные связи С-Н. ..F.

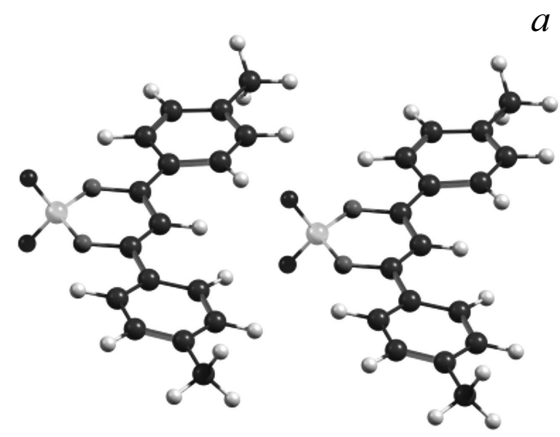

$a$

Рис. 7. Строение димеров в кристалле 1: $(a)$ „голова-голова“, $(b)$ „голова-хвост“.

помощи квантово-химического моделирования оценили взаимодействие в стопке (димер „голова-голова“) и в слое (димер „голова-хвост“) (рис. 7). Расчет полной энергии для димеров проводили методом РСМ для экспериментальной геометрии. Более выгодным является димер „голова-хвост“" (таблица) за счет образования водородной связи С-H...F (рис. 6,b). Энергия разрушения димера „голова-голова“ на порядок меньше по сравнению с димером „голова-хвост“ (таблица). Соответственно при растворении кристалла в первую очередь происходит разрушение стопочных структур и наблюдается формирование супрамолекулярных ленточных структур, в которых молекулы 1 соединяются C-H...F-связями. Именно ленточное строение агрегатов 1 в растворе объясняет отсутствие эксимерной люминесценции в отличие от кристаллов $(520 \mathrm{~nm})$ [13].

Для молекулы $\mathbf{1}$ по данным расчетов оптимальной является структура с плоскостью симметрии по линии атом бора - центральный атом углерода хелатного цикла. Значение полной энергии молекулы 1 с экс- 
периментальной геометрией выше, чем оптимальной геометрии на 0.03 at.units

\section{Выводы}

Изучены процессы формирования Ј-агрегатов при растворении кристаллов 1 и последующей их диссоциации методами абсорбционной и люминесцентной спектроскопии и квантово-химического моделирования.

Результаты исследования показали, что процесс растворения 1 состоит из трех стадий: 1) отрыв от кристалла фрагментов не менее 3-5 молекул (минимальное количество для образования Ј-агрегатов) и их сольватация; 2) расщепление Ј-агрегатов на отдельные сольватированные молекулы; 3) переход молекул в состояние, соответствующее минимуму энергии. Первая стадия (собственно растворение кристалла) проходит за несколько минут. Для второй стадии необходимо уже несколько часов, благодаря чему удается наблюдать Jагрегаты в спектре поглощения разбавленных растворов.

\section{Финансирование работы}

Работа выполнена в рамках государственного задания Министерства науки и высшего образования Российской Федерации (тема № 0205-2021-0001).

\section{Список литературы}

[1] A. Sakai, M. Tanaka, E. Ohta, Y. Yoshimoto, K. Mizuno, H. Ikeda. Tetrahedron Lett., 53, 4138 (2012). DOI: $10.1016 /$ j.tetlet.2012.05.122

[2] A.G. Mirochnik, B.V. Bukvetskii, E.V. Gukhman, V.E. Karasev. J. Fluoresc., 13 (2), 157 (2003). DOI: $10.1023 / \mathrm{A}: 1022939209971$

[3] X. Zhang, R. Lu, J. Jia, X. Liu, P. Xue, D. Xua, H. Zhoua. Chem. Commun., 46, 8419 (2010) DOI: $10.1039 / \mathrm{C} 0 \mathrm{CC} 03448 \mathrm{G}$

[4] H. Wu, L. Xue, Y. Shi, Y. Chen, X. Li. Langmuir., 27 (6), 3074 (2011). DOI: 10.1021/la104888p

[5] А.Г. Мирочник, Е.В. Федоренко, Д.Х. Шлык. Журн. физич. химии., 81 (11), 2096 (2007) [A.G. Mirochnik, E.V. Fedorenko, D.H. Shlyk, V.E. Karasev. Rus. J. Phys. Chem., 81 (11), 1880 (2007). DOI: 10.1134/S0036024407110295].

[6] Y.L. Chow, C.J. Johansson. J. Phys. Chem., 99 (49), 17566 (1995).

[7] W.A. Morris, T. Butle, M. Kolpaczynska, C.L. Fraser. Mater. Chem. Front., 1, 158 (2017). DOI: 10.1039/C9QM00518H

[8] T. Butler, W.A. Morris, J. Samonina-Kosicka, C.L. Fraser. ACS Appl. Mater. Interfaces, 8, m242 (2016). DOI: $10.1021 /$ acsami.5b09688

[9] А.Г. Мирочник, Е.В. Федоренко. В.Е. Карасев. Изв. АН. Сер. хим., 57(6), 1168 (2008). [A.G. Mirochnik, E.V. Fedorenko, V.E. Karasev. Russ. Chem. Bull, 57 (6), 1190-1193 DOI: 10.1007/s11172-008-0149-x].

[10] E.V. Fedorenko, A.G. Mirochnik, I.B. Lvov, V.I. Vovna. Spectrochim. Acta A., 120, 119 (2014).

DOI: $10.1016 /$ j.saa.2013.10.016
[11] Б.В. Буквецкий, Е.В. Федоренко, А.Г. Мирочник. Изв. АН. Сер. хим., 62(9), 1991 ( 2013). [B.V. Bukvetskii, E.V. Fedorenko, A.G. Mirochnik. Russ. Chem. Bull., 62 (9), 1991 (2013). DOI: 10.1007/s11172-013-0289-5].

[12] G. Weber. Biochem. J., 75 (2), 335 (1960). DOI: $10.1042 / \mathrm{bj} 0750335$

[13] А.Г. Мирочник, Е.В. Федоренко. Опт. и спектр., 123(3), 365 (2017). DOI: 10.7868/S0030403417090252 [A.G. Mirochnik, E.V. Fedorenko. Opt. Spectr., 123 (3), 365 (2017) DOI: 10.1134/S0030400X17090247].

[14] Б.В. Буквецкий, Е.В. Федоренко, А.Г. Мирочник, А.Ю. Белолипцев Журн. структур. химии, $53(1), 139$ (2012). [B.V. Bukvetskii, E.V. Fedorenko, A.G. Mirochnik, A.Yu. Beloliptsev. J. Struct. Chem., 53 (1), (2012). DOI: $10.1134 / \mathrm{S} 002247661201009 \mathrm{X}$.

[15] M.W. Schmidt, K.K. Baldridge, J.A. Boatz. et al. J. Comput. Chem., 14 (11), 13 (1993). DOI: 10.1002/jcc.540141112

[16] E.V. Fedorenko, A.G. Mirochnik, A.Yu. Beloliptsev. J. Lumin., 196 (4), 316 (2018). DOI: 10.1016/j.jlumin.2017.12.071

[17] П. Прингсгейм. Флуоресценция и фосфоресценция. М.: Изд-во иностранной литературы, 1951. 622 с. [P. Pringsheeim. Fluorescence and Phosphorescence. New York-London, 1949].

[18] А.И. Китайгородский. Молекулярные кристаллы. М.: Наука, 1971. 424 c.

[19] D. Rohde, C.-J. Yan, L.-J. Wan. Langmuir., 22 (10), 4750 (2006) DOI: $10.1021 / 1 a 053138+$ 